\title{
Effects of Two Types of Dietary Fibre on Faecal Steroid and Lipid Excretion
}

\author{
R. L. WALTERS, I. MCLEAN BAIRD, \\ D. A. T. SOUTHGATE, J. GREEN, B. MORGAN \\ M. J. HILL, \\ B. S. DRASAR,
}

British Medical fournal, 1975, 2, 536-538

\section{Summary}

Fibre supplements from wheat bran and sugar cane residue (bagasse) were added to the normal diet of volunteers for 12-week periods in a controlled metabolic study. Stool weights and stool fat excretion increased on both dietary fibres. Bagasse increased the daily loss of acid steroids, but bran failed to affect bile acid excretion. Decreased transit time without alteration in faecal flora occurred with bagasse. The raised excretion of bile acids and fatty acids failed to lower the plasma cholesterol and triglycerides after 12 weeks. Thus different fibre sources with variable components have dissimilar metabolic effects.

\section{Introduction}

An inadequate intake of dietary fibre has been implicated on epidemiological grounds in the aetiology of many diseases common in Western communities, ${ }^{12}$ including coronary heart disease $^{3}$ and colorectal cancer. ${ }^{4}$ Nevertheless, epidemiological evidence on the aetiology of colorectal cancer is contradictory ${ }^{5}$ and many other factors are possibly concerned in the aetiology of coronary heart disease. ${ }^{6}$

Dietary fibre's protective effect against the development of atheroma may be due to the adsorption of bile salts by a component such as lignin, ${ }^{78}$ leading to an overall increase in cholesterol turnover and a decrease in serum cholesterol. Heaton et al., ${ }^{\circ}$ however, could not confirm adsorption in vivo. An alternative hypothesis is that dietary fibre supplements increase the volume of small intestine contents and make them colloidal, thus sequestering and diluting bile salts. Simultaneously, more rapid transit would carry an increased proportion of the bile salts past the preferential site of absorption-the distal ileum. ${ }^{10-12}$

The production of carcinogens or cocarcinogens by bacterial degradation of bile acids in the large intestine may be important in the aetiology of colorectal cancer. ${ }^{13}$ The modification of such a mechanism by dietary fibre may be due to dilution of bile salt substrate or potentially carcinogenic degradation products. Furthermore, the increased rate of large intestinal transit would allow less time for degradation to occur and carcinogens to act

West Middlesex Hospital, Isleworth, Middlesex

R. L. WALTERS, M.B., M.R.C.P., Research Registrar

I. MCLEAN BAIRD, M.R., F.R.C.P., Consultant Physician

P. S. DAVIES, M.B., M.R.C.P., Senior Registrar

Bacteriology Metabolism Research Laboratory, Central Public Health Laboratories, London NW9 5DX

M. J. HILL, B.SC., PH.D., Principal Biochemist

B. S. DRASAR, B.SC., PH.D., Senior Scientist

Dunn Nutritional Laboratory, Cambridge CB4 1 XJ

D. A. T. SOUTHGATE, B.SC., PH.D., Biochemist

Beecham Pharmaceuticals Research Division, Nutritional Research Centre, Tadworth, Surrey

J. GREEN, PH.D., F.R.I.C., Senior Research Associate

B. MORGAN, PH.D., A.R.I.C., Principal Scientific Officer

on the mucosa. ${ }^{4}$ The presence of dietary fibre in the large intestine alters the physicochemical environment in several ways, which may have some more direct effect on bacterial flora and their metabolic activity.

Dietary fibre is made up of several components, each of which may have a different effect in the gastrointestinal tract. We examined the effects of two different dietary fibres - the residue from sugar cane (bagasse) and wheat bran-on stool weight and faecal excretion of acid, neutral steroids, and lipids. We report here also the effects of bagasse on plasma cholesterol and triglyceride levels, gastrointestinal transit, and faecal bacterial flora.

\section{Methods}

BAGASSE STUDY

Nineteen nuns volunteered for a long-term dietary study after the nature and purpose of the investigation had been explained to them. Normal diet was allowed throughout the investigation. After initial control observations nine nuns were given a supplement of $10.5 \mathrm{~g}$ of bagasse in biscuit form, and the other 10 were given control biscuits which were low in fibre. The bagasse was ground so that most of the particles passed through a $0.7-\mathrm{mm}$ mesh. After 12 weeks the dietary regimens were crossed over for an equal period, after which final control observations were made while the volunteers took a normal diet.

Blood samples were taken every two weeks for plasma cholesterol and triglyceride measurements. Four stool samples were collected for bacteriological analysis in each dietary period. Two consecutive three-day stool collections were analysed for faecal steroids and total fat during the latter half of each dietary period. Gastrointestinal transit time was estimated by using a radio-opaque pellet method during each dietary period. The volunteers also noted the first appearance of a carmine marker. Transit measurements were repeated several times using carmine during each dietary regimen.

During the second period replicates of the diets eaten by five nuns from each group were collected on two days for analysis for dietary fibre constituents.

\section{BRAN STUDY}

Another five volunteers, under metabolic ward conditions and receiving low fibre diets, were given a supplement of $39 \mathrm{~g}$ of wheat bran as biscuits. Most of the wheat bran particles passed through a 0.84-mm mesh, which was a similar particle size to the bagasse. These biscuits were compared with low-fibre control biscuits, the order of administration being varied. After a four- to five-day lead-in period diet replicates and stools were collected for a week. We report here the effects on stool weight and steroid and fat excretion. (These studies will be reported fully elsewhere.)

\section{ANALYTICAL METHODS}

The bacterial flora were determined by the methods of Drasar and Crowther, ${ }^{14}$ with the assignation of non-sporing anaerobes to genera by Peach et al.'s method. ${ }^{15}$ Faecal solids were measured by drying in an air-oven (bagasse study) or freeze drying (bran study).

Faecal acid and neutral steroids were assayed as described by Hill and Aries, ${ }^{16}$ and total fat estimation was by the method of Southgate. ${ }^{17}$ Plasma cholesterol and triglycerides were measured by autoanalyser (Technicon methods N24a and N78).

Bowel transit times were measured with radio-opaque pellets. ${ }^{18}$ The $80 \%$ transit times were determined graphically and the results 
TABLE I-Effects of Bagasse Supplements. Results are Means \pm S.E. P Values were Calculated on Paired t Test Comparisons

\begin{tabular}{|c|c|c|c|c|}
\hline & No. of Subjects & Control Biscuit & Bagasse Biscuit & $\mathbf{P}$ \\
\hline $\begin{array}{l}\text { Plasma cholesterol (mmol/1) } \\
\text { Plasma triglyceride (mmol/1) } \\
\text { Gastrointestinal transit (hours): } \\
\text { Radio-opaque pellet method } \\
\text { Carmine dye method } \\
\text { Faecal wet weight (g/day) } \\
\text { Faecal dry weight (g/day) } \\
\text { Faecal acid steroid concentration (mg/g dry stool) } \\
\text { Faecal acid steroid excretion (mg/day) } \\
\text { Faecal neutral steroid concentration (mg/g dry stool) } \\
\text { Faecal neutral steroid excretion (mg/day) } \\
\text { Faecal total fat excretion (g/day) }\end{array}$ & $\begin{array}{r}19 \\
19 \\
18 \\
18 \\
9 \\
9 \\
9 \\
9 \\
9 \\
9 \\
9\end{array}$ & $\begin{array}{r}5.71 * \\
0.84^{*} \\
46.6 \pm 6.4 \\
40.6 \pm 6.8 \\
88.3 \pm 6.4 \\
21.7 \pm 1.7 \\
7.1 \pm 0.9 \\
155.6 \pm 20.0 \\
19.6 \pm 1.9 \\
419.9 \pm 50.8 \\
4.3 \pm 0.5\end{array}$ & $\begin{array}{r}5 \cdot 70^{*} \\
0.83^{*} \\
36 \cdot 9 \pm 2.9 \\
27 \cdot 7 \pm 2.9 \\
139 \cdot 7 \pm 10 \cdot 2 \\
32.9 \pm 1.5 \\
7.1 \pm 0.4 \\
233.6 \pm 16.4 \\
11.5 \pm 0.3 \\
376.9 \pm 12.9 \\
6.7 \pm 0.5\end{array}$ & $\begin{array}{l}\text { N.S. } \\
<0.01 \\
<0.005 \\
<0.001 \\
<0.001 \\
<0.005 \\
<0.005\end{array}$ \\
\hline
\end{tabular}

*S.E. omitted because of skewed distribution.
Conversion: SI to Traditional Units.-Cholesterol: $1 \mathrm{mmol} / 1 \approx 38.6 \mathrm{mg} / 100 \mathrm{ml}$. Triglyceride: $1 \mathrm{mmol} / 1 \approx 88.5 \mathrm{mg} / 100 \mathrm{ml}$.

TABLE II-Effects of Bran Supplements. Results are Means \pm S.E.

\begin{tabular}{|c|c|c|c|c|}
\hline & No. of Subjects & Control Biscuit & Bagasse Biscuit & $\mathbf{P}$ \\
\hline $\begin{array}{l}\text { Faecal wet weight (g/day) } \\
\text { Faecal dry weight (g/day) } \\
\text { Faecal acid steroid concentration (mg/g dry stool) } \\
\text { Faecal acid steroid excretion (mg/day) } \\
\text { Faecal neutral steroid concentration (mg/g dry stool) } \\
\text { Faecal neutral steroid excretion (mg/day) } \\
\text { Faecal total fat excretion ( } \% \text { intake) }\end{array}$ & $\begin{array}{l}5 \\
5 \\
4 \\
4 \\
4 \\
4 \\
4\end{array}$ & $\begin{array}{r}92 \cdot 6 \pm 10 \cdot 1 \\
22.9 \pm 1.5 \\
8.6 \pm 0.7 \\
199.0 \pm 43.9 \\
27.6 \pm 1 \cdot 1 \\
646.0 \pm 73.2 \\
3.2 \pm 0.3\end{array}$ & 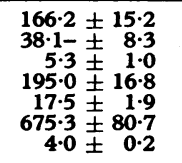 & $\begin{array}{l}<0.005 \\
<0.01 \\
<0.01 \\
<0.01 \\
\text { N.S. }\end{array}$ \\
\hline
\end{tabular}

expressed as average time for the passage of the first $80 \%$ of the pellets. Carmine was given at standardized times in a dose sufficient to colour the stools (usually $500 \mathrm{~g}$ ).

The components of the dietary fibre in diets and faeces were measured by slight modifications of Southgate's procedure. ${ }^{12}$

\section{Results}

BAGASSE STUDY

The basic diets of the volunteers provided about $18.5 \mathrm{~g} /$ day of dietary fibre, most of which was hemicellulose. The addition of bagasse biscuits increased the total dietary fibre by nearly $9 \mathrm{~g} /$ day. Dietary collections made for two days, however, give only an approximate estimate of the changes produced by the addition of bagasse. The bagasse supplement contained $4 \mathrm{~g}$ of cellulose and lignin, whichalmost doubled the volunteers' daily intake of those fibre components. The bagasse we used contained $92 \%$ fibre but less lignin than other reported samples. ${ }^{20}$

The bagasse had a moderate bulking effect, stool dry weight being increased by $50 \%$ and stool wet weight by nearly $60 \%$ (table I). The total faecal loss of neutral steroids was unaltered by the bagasse and consequently their concentration in the stool was reduced.

The fibre supplement caused an increased daily loss of acid steroids, but their concentration was virtually unchanged owing to the increase in faecal bulk. There was also an increased daily loss of fatty acids, which indicated that the excretion-promoting effect was not necessarily specific to bile acids. The raised excretion of bile and fatty acids did not cause lowering of plasma cholesterol and triglyceride levels, even after 12 weeks.

Though the gastrointestinal transit time was significantly reduced by the bagasse (table I) and there were physicochemical changes in the faeces the composition of the stool flora did not change; the number of viable bacteria per gram of faeces and the relative numbers of aerobes and anaerobes, both sporing and non-sporing, were unchanged. The metabolic activity of the clostridia seemed not to change. Also, no change in degradation of acid or neutral steroids could be shown.

\section{BRAN}

Dietary analyses showed that the average control level of dietary fibre, $14 \mathrm{~g}$, was increased to $27 \mathrm{~g}$ by the bran supplement, and just over $3 \mathrm{~g}$ of the $13 \mathrm{~g}$ increment was contributed by cellulose and lignin. In contrast to the bagasse results, dilutional effects were observed for both acid and neutral steroids-though there was no difference in the amount of degradation of neutral steroids between fibre and control regimens. Faecal fat excretion was increased on the bran diet but not significantly.

\section{Discussion}

The two fibres we used differ in several respects. Bagasse fibre contains a high proportion of cellulose and lignin, while bran fibre consists principally of hemicellulose and, unlike bagasse, contains many constituents other than dietary fibre.

Our results obtained with bran on stool weight and bile acid excretion agree with those of Eastwood et al. ${ }^{21}$ The lack of an increase in bile acid excretion makes the changes of biliary lipids observed by Pomare et al. ${ }^{22}{ }^{23}$ explicable only by some other alteration in the enterohepatic treatment of bile salts and their precursors.

Though both fibres produced bulking effects and increased the excretion of fatty acids their effects on steroid excretion were different, probably owing to differences in their chemical composition. Lignin may not be of prime importance in increasing the excretion of bile acids, since, in vitro, this component contributes only slightly to the total bile acid binding capacity of bagasse. ${ }^{24}$

More attention should be paid to testing a variety of precisely defined dietary fibres obtained from different sources. For instance, the physicochemical effects of substances such as cellulose $^{1125}$ and psyllium colloid ${ }^{1-12}$ on the intestinal contents may be important in the apparent ability of these materials to sequester bile salts in vivo. The mechanism of such sequestration is completely hypothetical. The way the fibre is prepared and, particularly, its particle size ${ }^{2426}$ affect its water holding and other physiological activities. But the particle size of the bagasse and the bran was similar, so this was unlikely to be the cause of the physiological differences between bagasse and bran. From such considerations it is hardly surprising that reports on the value of dietary fibre in lowering serum cholesterol conflict. ${ }^{25}{ }^{27-33}$ Also, trials are apt to be influenced by other variables-for example, seasonal trends ${ }^{31}$ and venesection techniques. ${ }^{34}$

The changes that bagasse and bran made in gastrointestinal transit and faecal bulk were not reflected in alterations in stool bacteriology or steroid degradation. But the changes were still compatible with a possible protective action of dietary fibre against mucosal damage by potential carcinogens from degraded bile acids (or other faecal constituents). Increased rate of transit of such substances or their dilution by increased faecal bulk, adsorption into fibre, or sequestration within a colloid matrix remain possible protective mechanisms, even without changes in the amount of acid steroid degradation.

We gratefully acknowledge grants from the Cancer Research Campaign, North West Metropolitan Regional Health Authority, Beecham Pharmaceutical Research Division, and the Medical 
Research Council, which enabled us to carry out this work. Tate and Lyle Ltd. were most helpful in supplying bagasse, which was prepared into biscuits by Smith's Flour Mills. Miss J. Fletcher, chief dietitian, West Middlesex Hospital, gave much help throughout the study and Mr. W. J. Branch provided invaluable technical help in the measurements of the dietary fibre.

\section{References}

${ }^{1}$ Cleave, T. L., Campbell, G. D., and Painter, N. S., Diabetes, Coronary Thrombosis and the Saccharine Disease, 2nd edn. Bristol, Wright, 1969. 2 Burkitt, D. P., Lancet, 1970, 2, 1237.

3 Trowell, $\dot{H}$. C., Revue Europeéne d'Études Cliniques et Biologiques, 1972, 17,345 .

${ }^{4}$ Burkitt, D. P., Cancer, 1971, 28, 3.

5 Drasar, B. S., and Irving, D., British fournal of Cancer, 1973, 27, 167.

Department of Health and Social Security, Diet and Coronary Heart Disease, Report on Health and Social Subjects, 7. London, H.M.S.O. 1974.

7 Eastwood, M. A., and Hamilton, D., Biochimica et Biophysica Acta, 1968, 152,165 .

${ }^{8}$ Eastwood, M. A., and Girdwood, R. H., Lancet, 1968, 2, 1170.

$\checkmark$ Heaton, K. W., Heaton, S. T., and Barry, R. E., Scandinavian fournal of Gastroenterology, 1971, 6, 281 . 10 Forman, D. T., et al., Proceedings of the Society for Experimental Biology

11 Stanley, M., et al., Gastroenterology, 1972, 62, 816.
}

${ }^{12}$ Beher, W. T., and Casazza, K. K., Proceedings of the Society for Experimental Biology and Medicine, 1971, 136, 253.

13 Aries, V., et al., Gut, 1969, 10, 334.

14 Drasar, B. S., and Crowther, J. S., in The Isolation of Anaerobic Organisms, ed. D. A. Shapton, and R. G. Board, p. 93. London, Academic Press, 1971.

15 Peach, S., et al., fournal of Medical Microbiology, 1974, 7, 213.

$16 \mathrm{Hill}$, M. J., and Aries, V. C., Fournal of Pathology, 1971, 104, 129.

17 Southgate, D. A. T., Fournal of the Science of Food and Agriculture, 1971, 22, 590 .

18 Hinton, J. M., Lennard-Jones, J. E., and Young, A. C., Gut, 1969, 10, 842.

19 Southgate, D. A. T., fournal of the Science of Food and Agriculture, 1969, 20,331 .

20 Southgate, D. A. T., unpublished observations.

21 Eastwood, M. A., et al., British Medical fournal, 1973, 4, 392.

${ }^{22}$ Pomare, E. W., and Heaton, K. W., British Medical fournal, 1973, 4, 262.

${ }^{23}$ Pomare, E. W., et al., Abstracts of the British Society of Gastroenterology, Autumn Meeting, 1974.

${ }^{24}$ Morgan, B., et al., British fournal of Nutrition, 1974, 32, 447.

25 Shurpalekar, K. S., et al., Nature, 1971, 232, 554.

${ }^{26}$ Kirwan, W. O., et al., British Medical fournal, 1974, 4, 187.

27 Garvin, J. E., et al., Proceedings of the Society for Experimental Biology and Medicine, 1965, 120, 744 .

28 Thiffault, C., Belanger, M., and Pouliot, M., Canadian Medical Association Fournal, 1970, 103, 165 .

29 Keys, A., Grande, F., and Anderson, J. T., Proceedings of the Society for Experimental Biology and Medicine, 1961, 106, 55.

${ }^{30}$ Mathur, K. S., Khan, M. A., and Sharma, R. D., British Medical fournal, $1968,1,30$.

31 Luyken, R., et al., Voeding, 1962, 23, 447.

32 Antonis, A., and Bersohn, I., American fournal of Nutrition, 1962, 10, 484.

32 Antonis, A., and Bersohn, I., American fournal of Nutrition,

${ }^{34}$ Heaton, K. W., and Pomare, E. W., Lancet, 1974, 1, 49. 1,336 .

\title{
Hostility to Kith and Kin
}

\author{
SIMON BEHRMAN
}

British Medical fournal, 1975, 2, 538-539

\section{Summary}

Ten male patients who shared a similar behaviour disorder have been seen. Their behaviour was characterized by extreme hostility towards close members of the family without aggressiveness towards others. The first manifestations of an increase in hostility may be acts aimed to injure or denigrate the spouse or close members of the family. The dynamics of Capgras's syndrome may be similar. This behaviour disorder must be recognized as one of many causes of conjugal conflict.

\section{Introduction}

It is a trite dictum that phenomena occurring in disease are but exaggerations of events which may be manifest in health. The cantankerousness displayed in the intimacy of the family circle is too common to attract attention. Habitual discord which is more than an occasional verbal sparring, and which may threaten the stability of the family, is also an everyday occurrence. "A little more than kin," and the odds are that the fellow creature will be "less than kind" (Hamlet $\mathrm{I}, \mathrm{ii}, 65)$.

My aim here is to draw attention to aggressiveness against the wife and other close relations which appears without valid reason after many years of happy conjugal relations. The begetter of this family discord is the husband who, however, seems to be totally free from irascibility in social intercourse outside his home. Because his malevolence is strictly circumscribed those who do not receive his abuses and taunts find it difficult,

if not impossible, to give credence to charges of cruelty made against a man who outside his home affects a personality entirely free from such traits. All the wives in this series found the incredulity of friends and social agencies embarrassing and distressing. When some wives, goaded by their husband's scorn-alternating with ostracism -eventually abandoned their husbands the latter were invariably taken completely by surprise. They lacked all insight into their past callous behaviour and were full of contrition. They clearly felt a deep affection for the spouses who had deserted them and were prepared to make amends.

\section{Patients}

Each of the 10 patients, ranging in age from 26 to 54 years, included in this series was submitted to a long interview during which all of them comported themselves with courtesy and politeness. It was only through meeting the spouse that the behaviour disorder within the bosom of the family came to light. Each wife described her husband's behaviour at home in practically the same terms. She claimed that the husband's behaviour thad changed profoundly from the premorbid pattern. The prominent feature was a newly developed aggressiveness directed against herself and close members of the family. This aggressiveness was characterized by quick temper, rudeness, anger, and suspiciousness, and sometimes physical assault. A reduction of interpersonal relations with refusal to communicate were features in some cases. In each case the marital history given by the spouse failed to show any significant premorbid disturbance of conjugal relations.

In six cases kith and kin hostility appeared after head injuries of varying degrees of severity. Cardiac arrest during open-heart surgery was followed in one case by signs of focal brain damage, which were associated with the first appearance of ihostility to members of the family. In two epileptic patients aggressiveness showed marked fluctuations which paralleled the epileptic state; scant temporal lobe seizures were associated with persistent interictal hostility of a similar circumscribed pattern. The following case illustrates the clinical features presented by this posttraumatic group of cases. 